\title{
Management employees working conditions for sustainable development in era of globalization
}

\author{
Viera Sukalova, ${ }^{1, *}$ \\ ${ }^{1}$ University of Zilina, Faculty of Operation and Economics of Transport and Communications, \\ Univerzitna 1, 01026 Zilina, Slovakia
}

\begin{abstract}
Research background: Human resources today are well the most important and valuable resource of a company, and therefore it is very important that the company constantly deals with the field of working conditions. Working conditions represent a convex set of conditions, factors and other elements affecting the worker who performs the assigned work tasks for the employer and significantly affect his productivity, wellbeing, health and loyalty to the employer. Currently, the field of working conditions has been hit hard by the Covid 19 pandemic. The company's goal in the field of working conditions should be to create the best possible working conditions that will provide employees with a suitable and quality working environment, damage to health at work and benefits to increase their comfort.

Purpose of the article: The aim of our article is to analyse the legal aspects of labour protection and working conditions in EU and Slovakia and to document on the Case study current problems of work management and also the impact of Covid 19 on employees' working conditions.

Methods: Analysis, Synthesis, Case study, Questionnaire

We analyzed the current legislation of the EU and Slovakia in the field of occupational safety and working conditions, and on the example of a case study and the use of a questionnaire survey, we identified problems in this area.

Findings \& Value added: Identification of current problem areas in the management of working conditions and design of a system solution for sustainable development.
\end{abstract}

Keywords: work condition; work protection; employee; management

JEL Classification: $J 21 ; J 24 ; J 28$

${ }^{*}$ Corresponding author: viera.sukalova@fpedas.uniza.sk 


\section{Introduction}

Companies operate in a global environment that changes every day. There are modifications in the field of legislation, quality standards, and continuous improvement of technology or social values. Such changes have the greatest impact on human resources, as they are in direct contact with them and must respond flexibly to them so that the company can successfully advance and develop. For this reason, investing in human resources and their working conditions is considered a safe way for employers to increase an organization's performance. (Blaga, 2020) The aim of our research is to identify, on the example of a case study, the current problems of working conditions in connection with a pandemic in a manufacturing company.

\section{Methodology}

The aim of our research was to analyse the perception of the level of the working conditions management by productive workers and administrative workers on an example of a Case study in the big-sized manufacturing company; the company operates in the field of metal production and has potential to grow in the future. The methodology of research includes literature review; desk review (to analyse secondary data, to research the latest theoretical and practical developments in management), analyse of company documents. Primary data were collected by self-administered questionnaire consisting thirty two questions, with verbal scale (Likert scale), as well as open questions focused on demographics, ageing, work conditions, work organisation, psychosocial aspects of work, work protection, technical aspects of work. The questionnaire was sent to 250 workers and was received by 168 workers (126 production employees and 42 administrative employees) which represented a return of $67,2 \%$. The study was focused on selected aspects of working conditions management from the point of view productive workers and administration.

\section{Results}

Human resources today are well the most important and most valuable resource of the company and therefore it is very important that the company constantly deals with the field of working conditions and tries to provide its employees with the best possible working conditions.

\subsection{Working conditions - essential part of human resource management}

Human resources today are well the most important and most valuable resource of the company and therefore it is very important that the company constantly deals with the field of working conditions and tries to provide its employees with the best possible working conditions. Working conditions represent a convex set of conditions, factors and other elements affecting the worker who performs the assigned work tasks for the employer and significantly affect his productivity, well-being, health and also loyalty to the employer. Zainon (2020) identifies employees as an important part of the company, necessary to fulfil the mission and achieve goals. He states that nowadays the achievement of business goals is significantly influenced by, for example, technological changes, market conditions, the economic situation, or the level of requirements imposed by the customer. Tomcikova and Coculova (2020) have a similar opinion, stating that all changes that occur are determined by one common fact, and that is the existence of human capital in the company. Human resources management should strive to achieve harmony between management practices 
and corporate objectives in the area of individual human resources management functions so that these objectives are met. It should also focus on their behaviour and its impact on business performance. (Tashtoush and Eyupoglu, 2020) Efforts in this direction are always closely linked to working conditions. The work environment is a summary of all material conditions of work (machinery and equipment, handling equipment, personal protective equipment, other workplace equipment, raw materials and materials, construction solutions), which together with other conditions (technology, work organization, social conditions of work) create factors - physical, chemical, biological, socio-psychological and other, affecting the worker during the work process. The composition and level of the working environment affect the well-being, performance, but also the health status of the employee. Challenging adaptation to an unfavourable work environment causes dissatisfaction or even resistance in the worker, which is usually reflected in his relationship with the employer. Personnel work in connection with the working environment should focus primarily on the spatial solution of the workplace, physical working conditions as well as socio - psychological working conditions. We define working conditions as a set of factors directly or indirectly affecting a person's health and work performance in the work process, which directly or indirectly condition the course and results of the work process, are influenced by the work regime, rest and the state of the work environment. This set consists of factors of the working environment: physical, chemical biological, which are the product of material and technical equipment of the workplace. Working conditions can be divided into immediately tangible and tangible conditions, such as work and operating facilities, premises, workplace equipment, work equipment, work aids, etc. and intangible conditions such as the organization of working hours, rest periods, work organization, degree of workload, responsibility, degree of independence, the level of care of the employer for the safety and health of his employees and the like. We can also distinguish between social conditions where interpersonal relations in the team in which the employee is included, interpersonal relations in the organization and relations with persons outside the organization with whom the employee comes into contact within the work.

\subsection{Legal aspects of working conditions}

Uniformity in the approach to the regulation of working conditions is ensured by international standards as well as national legislation. The Universal Declaration of Human Rights is a United Nations document, Article 23 of which states that everyone has the right to work and to free choice of employment, to just and favourable conditions of work and to protection against unemployment. The European Framework Directive on the introduction of measures to encourage improvements in the safety and health of workers at work (Directive 89/391 / EEC), adopted in 1989, guarantees minimum safety and health requirements throughout Europe, while Member States may maintain those measures or introduce more stringent measures. It states that employers are obliged to ensure the safety and health of their workers. In the shadow of the COVID-19 pandemic, the European Union has also created the EU4Health program as a quasi-commitment to health and safety at work, which serves to support and strengthen the national health systems of the member states. (Polomarkakis, 2020) The basic source for the regulation of working conditions and protection of employees in the Slovak Republic is normative legal acts, especially the Constitution of the Slovak Republic, laws and legal regulations issued for their implementation. The provision of Article 36, which states that employees have the right to fair and satisfactory working conditions, is particularly important in the field of working conditions. The Constitution of the Slovak Republic provides special protection in employment relations to women, juveniles and persons with disabilities. The Labour Code 
regulates individual employment relationships in connection with the performance of dependent work of natural persons by legal entities or natural persons, as well as collective employment relationships. Satisfactory working and living conditions of employees ensured by the employer are one of the preconditions for the proper, undisturbed performance of work tasks arising from the type of work agreed within the employment relationship. In order to improve the work culture and working environment, the Labour Code obliges employers to create adequate working conditions and to take care of the appearance and adaptation of workplaces, social facilities and personal hygiene facilities. The application of occupational health and safety requirements in the Slovak Republic is defined by the currently valid Act no. 124/2006 Coll. as amended by later regulations on safety and health at work. (Sukalova, 2005)This Act establishes the general principles of prevention and basic conditions for ensuring occupational safety and health and for the exclusion of risks and factors conditioning the occurrence of accidents, occupational diseases and other damage to health at work.

\subsection{Impact of Pandemic Covid 19 on working conditions}

The Covid 19 pandemic affected all spheres of life and, to a large extent, the world of work and the management. During this period, human resource management mostly moved to the online sphere. Employees who were allowed to do so by the nature of the work remained to work from home. Personal contact has been replaced in many companies by e-mail communication or video conferencing. As a result, the importance of human resources increased significantly during the pandemic. At present, their main task is to maintain the productivity and motivation of employees and to contribute to maintaining their well-being. Gigauri (2020) describes the pandemic as a factor that makes a positive contribution to human resource management, in particular by accelerating the digitization process in companies so that employees can carry out their work activities during this period as well. It also emphasizes that human resources are under greater pressure during the crisis, which is increasing the personal stress of workers. Singh (2020), like Gigauri, states in his article that there have been significant changes in human resource management during the pandemic, especially digitization, as companies have had to create a space for employees to work from home practically from day to day. COVID-19 has resulted in unprecedented challenges for workers' safety, health and well-being. Managers must communicate clearly, consistently, transparently, and empathetically with all employees about policies, programs, and procedures that protect their health from COVID-19 to reduce their sense of insecurity and health concerns (Dennerlein, et al., 2020). Within the area of working conditions, the central element of worker health protection is effective infection control in the workplace in order to eliminate or at least reduce the possibility of COVID-19 exposure to workers. These include technical inspections, e.g. increased fresh air ventilation and highly efficient air filters to reduce airborne pathogens. This also includes ensuring the testing of workers and monitoring contacts to ensure the safety of workers. At the same time, the period of the Covid 19 pandemic necessitated a massive expansion of work from home - the home office, which in the amendment to the Labour Code is named as work performed from an employee's household. Work performed from home has ceased to be a benefit for the employee, and in many workplaces of the employer it has become a matter of course from an epidemiological point of view as well as a necessity. (Barancová, 2020). We can say that working from home can have a positive effect on the work commitment of workers, higher levels of absorption, individual commitment and work-related enthusiasm, a feeling of greater self-efficiency at work and flexibility of work, which in turn can lead to reduced perception of work fatigue and subsequently lead to recasting. Work-related fatigue, in turn, shows that the ability to cope with individual workloads and demanding time pressures, 
which upset the balance between personal and private life, are often impaired, especially for those categories of people who are more exposed to family responsibilities, such as parents and carers of elderly relatives (Palumbo, 2020). Working from home is difficult for employees because they do not feel the organizational climate at home, they are unfocused as a result of frequent disturbance by family members, and for this reason conflicts arise between work and private life. (Chanana and Sangeeta, 2020) In industry, the working conditions of systems are complicated. It may contain some adverse/favourable factors that can damage/improve components' reliabilities compared to that in the designed working condition. The same product system may also work in different conditions; then the reliability of the system is not only determined by system structure, components' designed reliabilities, etc. It can be also influenced by its working condition. (Chen and Zhu, 2019) Improper working conditions and various types of hazards in working place cause the need to humanize work in many enterprises. First of all, it means the necessity of adjusting the safety of work activities to operating and required standards. (Polek-Duraj, 2020) Perceived working conditions lead to various negative outcomes for employee behaviours, including turnover intentions. (Arnoux et al., 2016) Perceived health and psychosocial factors, rather than work conditions, explained the association between the presence of chronic health condition and work ability. (Koolhaas et al., 2014) I tis necessary to pay attention to the involvement of workers and unions in the process of creating workplace-specific COVID19 Safety Plans, or health and safety procedures. Stronger, enforceable health and safety protections for workers that include workplace-specific COVID-19 Safety plans designed in collaboration with workers. (Sugerman-Brozan, 2020)

\section{Research results and discussion}

We examined issues related to working conditions management on the example of big sized international company in the field of machinery industry. We introduce selected aspects of the search in production (126 respondents of the production staff) and in administration (42 administrative workers). In the production part, the company provides production employees with various types of working time arrangements; it is a single-shift, two-shift, three-shift and continuous operation. The company tries to meet the needs of employees if the assigned type does not suit them for objective reasons. Breaks at work are set well for various types of change and provide employees with sufficient rest, while providing employees with benefits such as coffee boxes and outdoor shelters for smokers, which increase employee comfort. The employer is obliged to notify the employee of the schedule of working hours, i.e. the allocation of one of the mentioned options or the change of the schedule of working hours, at least one week before their implementation. Not everyone is comfortable with such a change. Flexible working hours are provided only for managers. Overtime work also occurs in production; its scope is based on the principles of the Labour Code. Overtime work therefore means work performed by employees on the order of the employer (up to a maximum of 150 hours in a calendar year) or with his consent (up to a maximum of another 250 hours in a calendar year) over a specified weekly working time resulting from a predetermined work schedule, thus from the work schedule. It follows from the above that the total number of hours of overtime work of an employee may not exceed 400 hours in a calendar year. $12 \%$ of employees stated that they worked more hours' overtime. The usual physical risks provided by preventive measures have outweighed the biological risk, but $76 \%$ of employees trust anti-covid measures in the workplace. According to $36 \%$ of respondents, anti-covid measures cause disproportionate discomfort during breaks at work. Current working conditions also affect the socio psychological well - being in the workplace. $36 \%$ of employees in production perceive increased stress at work, mainly due to the pandemic and pandemic measures, as well as for fear of becoming infected at work. Socio-psychological working conditions are also related 
to whether a person works in constant contact with other workers or works in isolation. Some work or work tasks require the continuous cooperation of several employees, others require cooperation only occasionally, and others are performed by the employee independently of the others. $53 \%$ of respondents consider socio-psychological well-being to be very good; $13 \%$ of employees as unsatisfactory, mainly due to conflicts in the workplace. $35 \%$ of the surveyed production employees do not consider information on occupational health risks to be sufficient and do not understand several established measures. The questionnaire survey was conducted also on a sample of 42 administrative employees; the sample consisted of 22 women and 20 men, aged 23 to 49 years. $53 \%$ of respondents stated that they were satisfied with the work in the form of Home Office, while $23 \%$ perceived this form negatively; only $9 \%$ of employees had experience with Home Office before the outbreak of the pandemic. A change in the work environment can have a significant effect on an employee's performance; 64\% of respondents said that their performance in the home environment was the same as in the office; $27 \%$ perceive their performance as lower, mainly due to unsuitable working conditions and ergonomics as well as disruptive influences from other household members. $9 \%$ of respondents perceive their performance as higher than standard conditions, mainly due to a better reconciliation of work and family life. Given that most respondents had little or no experience of working from home in the form of a Home Office, we can assume that they do not have a home environment sufficiently adapted for undisturbed work from home and also probably do not have established work habits for working from home. In addition, the overall situation caused by the COVID-19 pandemic brought specific elements that prevent workers from concentrating fully, for example, for closed schools and kindergartens, children were at home most of the time and parents had to take care of them. Interestingly, $7 \%$ of respondents said they were given more tasks and more controlled than in the office. Given that the vast majority stated that they receive the same number of work tasks as when working in the workplace, it may be a subjective feeling of these respondents, or a shortterm negative situation, which will improve later. Almost all employees take breaks at work while working in the form of a Home Office, so we can assume that they know how to spread their working time as it suits them with regard to sufficient rest. Most respondents, $\mathrm{t}$. j. $38.1 \%$ of the total stated that they get used to taking one big break for lunch and several small breaks at work. The second largest group of respondents, representing $27 \%$ of the total, stated that they get used to taking only one big break for lunch, which in our opinion can contribute to a higher degree of work concentration and job creation and favourable work habits and routines, but regularity and divide working time correctly to avoid too long a continuous workload. Another group representing 21\% stated that they preferred several short breaks. In this type of break planning, care must be taken to ensure that they are adequately rested while not distracting the employee too much or reducing his or her productivity. In terms of technical equipment, all respondents had a company laptop; the problem was a sufficiently large office desk suitable in 35\%; $48 \%$ reported an unsuitable chair; $8 \%$ slow internet. In terms of psycho-social, $62 \%$ of respondents stated the same level of work stress as in the office, the second largest group of respondents (29\%) stated that working from home in the form of a Home Office is less stressful for them than office work. We evaluate this fact positively, because despite various complications associated with switching to a completely new or little practiced system of work for most respondents, the home environment increases the mental well-being of workers and reduces their stress compared to their normal type of work. Regarding the stress factors, most respondents representing $57 \%$ of the total chose the factor of reconciling work and private life. We can therefore consider this factor to be the most stressful of these options. This factor can be serious, for example, for parents who, in addition to performing assigned work tasks, also had to take care of their children who were at home as a result of closed schools and 
kindergartens. $47 \%$ of respondents chose the option of online contact with superiors or coworkers, so we can consider it as the second most stressful factor. Communication in an online environment can often be complicated by computer errors, and is usually less pleasant than direct contact, which can contribute to increased employee stress. The third most chosen option was the difficulty of work tasks, chosen by $34 \%$ of respondents. It may be a subjective view, but it is likely that some work tasks are more difficult to perform when working from home, for example due to more difficult communication or more limited access to sources of information. Administrative staff shows a higher level of complaints about the difficulties of the musculoskeletal system. They were also not sufficiently informed about the risks of working at home, there is probably a lack of risk analysis.

\section{Conclusion}

The global environment brings constant changes and with them new demands on management, works organization and sustainability of working conditions for production workers as well as for administrative staff. This study confirms that even with a formal declaration of correct management of working conditions; shortcomings occur in the area of production as well as administrative workers. Our research shows that the company does not use all the options under the labour code, for example does not provide the opportunity to work in divided jobs. This type of job would be advantageous, for example, for mothers or fathers who are caring for a minor child or for a worker who is caring for sick relatives and does not have enough free time to work the whole work shift. Flexible forms of work that can be a starting point for employees, although their employer often sees them as a complication. It is also necessary to thoroughly perform a risk analysis, including psychosocial ones, and to comply with the information obligation of the employer. The company should set criteria and parameters that the home work environment must meet in order to meet the technical, spatial, ergonomic, safety requirements for comfortable, safe and efficient work of workers. It should also monitor compliance with these criteria, even if they are not met, to help remedy shortcomings. The pandemic tested the ability of companies to adapt to sudden changes and confirmed that only systemic solutions can bring positive results in working with people - the most valuable capital. The pandemic has worsened working conditions, brought new biological risks. In practice, it turns out that the declared state of working conditions may not be in line with their perception by employees. From a formal approach, it is necessary to focus more on strict adherence to changing regulations, analyse occupational risks and emphasize the psychosocial aspects of work and constant dialogue with employees. It is useful to introduce the concept of socially responsible business. Next research will be focused on the health consequences of a pandemic for employees in manufacturing companies.

\section{Acknowledgement}

This paper is an output of the Science Project VEGA no. 1/0064/20. Behaviourism in a socially responsible communication strategy of enterprises.

\section{References}

1. Alexandris Polomarkakis, K. (2020). Health and safety at work in the time of COVID19: A social Europe reckoning?. European Jornal of Risk Regulation, 11(4), 864-883. 
2. Arnoux-Nicolas, C. ,Sovet, L., Lhotellier, L., Di Fabio, A., \& Bernaud, J.L. (2016). Perceived Work Conditions and Turnover Intentions, The Mediating Role of Meaning of Work, 7(704).

3. Barancova, H. (2020). COVID-19 a renesancia domáckej práce. Právny obzor, 103(4). 243-257.

4. Blaga, P. (2020). The Importance of Human Resources in the Continuous Improvement of the Production Quality. Procedia Manufacturing, 6(46), 287 - 293.

5. Dennerlein, J.T. (2020). An Integrative Total Worker Health Framework for Keeping Workers Safe and Healthy During the COVID-19 Pandemic. Human factors, 62(5), 689-696.

6. Gigauri, I. (2020). Influence of Covid-19 Crisis on Human Resource Management and Companies' Response: The Expert Study. International Journal of Management Science and Business Administration, 6(6), 15-24.

7. Chanana, N. \& Sangeeta, (2020), Employee engagement practices during COVID-19 lockdown. Journal of Public affairs.

8. Chen, Z.Q. \& Zhu, X.Y.(2019). Working-Condition Importance Measures for MultiComponent Systems. Book Series International Conference on Industrial Engineering and Engineering Management IEEM, (pp.1124-1128).

9. Koolhaas, W., Klink, J.J.L., Boer, M.R., \& Brouwer, S. (2014). Chronic health conditions and work ability in the ageing workforce: the impact of work conditions, psychosocial factors and perceived health. International archives of occupational and environmental helath, 87(4), 433-443.

10. Palumbo, R. (2020). Let me go to the office! An investigation into the side effects of working from home on working-life balance. International journal of public sector management, 33(6-7), $771-79$.

11. Polek-Duraj, K. (2020). Humanization of Work and Working Conditions On Regional Basis(Case Study). Innovation management and education excellence through vision 2020, I-XI, 2966-2974.

12. Singh, M. (2020). Impact of Covid-19 on HR practices and future workforce. Avaliable at: https://hr.economictimes.indiatimes.com/news/industry/impact-of-covid19-on-hr-practices-and-future-workforce/75653859

13. Sugerman-Brozan J. (2020). Measures to protect the health and safety of Massachusetts employeeswhomustwork at the workplaceduring the SARS-CoV-2 Pandemic. New solutions - a journal of environmental and occupational healthpolicy, 30(3), 249-253.

14. Sugerman-Brozan J. (2020). Health Technical Committee of the Massachusetts Coalition for Occupational Safety and Health. Measures to Protect the Health and Safety of Massachusetts Employees Who Must Work at the Workplace During the SARS-CoV-2 Pandemic. New Solut, 30(3), 249-253.

15. Sukalova, V. (2015). Personálny manažment. DOLIS.

16. Tashtoush, L. \& Eypupoglu, S. Z. (2020). The relationship between human resource management practices and organisational citizenship behaviour. South African Journal of Business Management, 42(51).

17. Tomcikova, L. \& Coculova, J. (2020). Leading and education of talented employees as one of the major impacts of globalization on human resources management. SHS Web of Conferences EDP Sciences, 8(74).

18. Zainon, S., Ismail, R. F., Ahmad, R., Shafi, R. M., Misman, F. N., Nawi, S., \& Kadir, J. M. A. (2020). Factors of Human Resource Management Practices Affecting Organizational Performance. International Journal of Organizational Leadership, 9(4). 